\title{
A MODELLING FRAMEWORK FOR RAILWAY INFRASTRUCTURE RELIABILITY ANALYSIS
}

\author{
C.J. Fourie ${ }^{1 *}$ \& N.T. Zhuwaki ${ }^{1}$
}

\section{ARTICLE INFO}

\section{Article details}

Submitted by authors 19 Apr 2017

Accepted for publication 3 Nov 2017

Available online $\quad 13$ Dec 2017

\section{Contact details \\ Corresponding author \\ cjf@sun.ac.za}

\section{Author affiliations}

1 Department of Industrial

Engineering, Stellenbosch University, South Africa

\section{DOI}

http://dx.doi.org/10.7166/28-4-1763

\begin{abstract}
The maintenance and management of railway infrastructure plays a central role in ensuring the reliability and availability of rail transport. In a highly competitive transport market, the rail industry is required to employ new and innovative maintenance strategies that will position rail transport as an affordable and reliable transportation alternative. This can be realised through implementing maintenance strategies that prioritise efficient resource allocation. Application of reliability-based techniques to make informed decisions in maintenance management, with an overall aim of reducing operational expenditure while maintaining safety and efficiency, has been increasing. This paper presents a framework for the application of a reliability-based technique to evaluate the reliability of railway infrastructure systems.
\end{abstract}

\section{OPSOMMING}

Die onderhoud en bestuur van spoorweginfrastruktuur speel ' $n$ sentrale rol om die betroubaarheid en beskikbaarheid van spoorverkeer te verseker. In 'n hoogs-mededingende vervoer bedryf, word dit van die spoorindustrie verwag om nuwe en innoverende onderhoudstrategieë toe te pas. Dit sal dié industrie in die posisie stel om 'n bekostigbare en betroubare vervoerkeuse te wees. Hierdie posisie kan egter slegs bereik word indien onderhoudstrategieë toegepas word wat voorkeur gee aan die doeltreffende toewysing van hulpbronne. Daar is ' $n$ toename in die toepassing van tegnieke gegrond op betroubaarheid vir die neem van ingeligte besluite in onderhoudbestuur. Die doel van die tegnieke is om bedryfsuitgawes te verminder terwyl veiligheid en doeltreffendheid behoue bly. In hierdie artikel word 'n raamwerk voorgestel vir die toepassing van tegnieke om betroubaarheid van spoorweginfrastruktuur te evalueer.

\section{INTRODUCTION}

The management of railway infrastructure assets involves a range of activities such as building, inspection, maintenance, enhancement, and renewal aimed at optimising the performance, risks, and costs of the infrastructure. This is a highly complex decision-making environment that requires various trade-offs. Furthermore, the relationship between the timing and choice of activities for multiple assets needs to be taken into account to achieve the required performance levels. Significant efforts have been made to develop decision support tools based on cost, risk, and reliability to assist with decision-making in highly complex asset management environments. Reliability analysis techniques allow valuable information to be extracted from infrastructure failure data to support maintenance and renewal decisions. Different systematic approaches have been proposed by McNaught [1], Jidayi [2], and Daniel and Conradie [3] as models to evaluate the reliability of rolling stock and railway track infrastructure respectively. Similarly, Panja and Ray [4] used reliability-based techniques to develop a parametric model to predict correctly the failure rate probability of point-and-point machines in railway signalling subsystems. Additionally, similar reliability analyses using fault tree analysis have been applied to railway infrastructure systems to quantify the reliability performance of railway electrical subsystems [5]-[7]. 
Despite the significant progress made in adopting a reliability-based approach to the maintenance and management of railway infrastructure assets, challenges remain in developing effective railway asset management decision support tools. These tools should take into account the various operational and functional characteristics of railway infrastructure systems. Improving the performance of individual infrastructure subsystems on their own will not contribute to the overall improvement of the infrastructure system. Instead, it results in the emergence of new behaviours at the subsystem boundaries. These new behaviours include unexpected interactions between the equipment and operations involved in the management of the system. Additionally, railway infrastructure systems are broad and complex, characterised by different technological and material properties. This presents challenges in defining the correct functional and operational configuration required to model the lifecycle performance of infrastructure systems. The benefits of prioritising, categorising, and improving intervention activities among the different infrastructure asset groups vary from improved infrastructure reliability performance to a reduction in operational and maintenance expenditures [8]. To improve the reliability performance of railway infrastructure systems effectively requires a whole-systems approach to railway infrastructure reliability modelling. This paper presents a holistic modelling methodology for evaluating the reliability performance of railway infrastructure assets. A holistic modelling methodology accounts for all the causes of unreliability that emerge at the interfaces and within the different asset groups that constitute railway infrastructure systems.

\section{RAILWAY INFRASTRUCTURE ASSET MANAGEMENT}

Infrastructure asset management is a broad description of three types of management issues: infrastructure investment management, infrastructure maintenance management, and infrastructure operations management [9]. These management issues involve the systematic and coordinated activities and practices through which an organisation optimally manages its assets. The activities focus on the performance, risks, and expenditures over the assets' lifecycle for the purpose of delivering the organisation's business objectives [10]. From these activities, the scope of decisions related to railway infrastructure asset management is observed to fall into two categories. The first category consists of decisions and activities that relate to maintenance, renewal, and infrastructure improvement. These decisions and activities extend to form a high-level strategy for the railway infrastructure assets through the delivery of work and the provision of train routes. Secondly, in addition to all aspects of maintaining, renewing, and improving railway infrastructure, the scope of asset management includes the operation of the network, which includes capacity planning and timetabling.

In railway infrastructure environments, asset management activities are planned and executed by developing appropriate strategies that focus on measurable infrastructure outputs such as availability or reliability. Corrective and preventive maintenance actions are examples of maintenance strategies employed in railway infrastructure asset management. Corrective maintenance recovers a system from asset failure. With this approach, a system is operated until an asset within the system fails. On the other hand, preventive maintenance centres on scheduling maintenance tasks with the aim of reducing the likelihood of asset failures. If the condition of an asset can be monitored, condition-based maintenance can be employed. This strategy dictates that maintenance should only be performed when certain indicators inferred from the asset present signs of an impending failure [11].

Generally, asset management emphasises achieving infrastructure outputs that are directed at meeting the needs and expectations of customers and key stakeholders. This requires the continuous and consistent gathering of information on the condition and performance of assets according to organisational objectives. Collecting information on asset performance makes the application of reliability-based techniques in infrastructure maintenance management possible. Ching and Leu [12] demonstrated this, using inspection data that reported on the operation and non-operation status of components. A framework was developed to estimate time-varying reliabilities of civil infrastructure assets that provided insight into the lifetime performance of infrastructure assets. To manage performance, it needs to be measured; hence performance indicators such as reliability are used to reflect the performance of complex systems. A reliability improvement programme for railway infrastructure assets focuses on performance and evaluation. The ability to measure the infrastructure quality on a continuous basis, and the ability to restore the infrastructure quality when it falls below acceptable levels, are two factors that influence the quality of infrastructure. In addition, maintaining infrastructure performance at acceptable levels requires increasing the 
physical capacity of the infrastructure system and employing consistent maintenance and management strategies that are centred on reliability improvement.

\section{UNDERSTANDING INFRASTRUCTURE INTERDEPENDENCIES}

The environment in which an infrastructure operates influences its operational performance. An infrastructure environment is a framework employed by the owners and operators of an infrastructure to ascertain goals and develop value systems for measuring the performance of their business. The framework also provides the ability to model and analyse operations to inform decision-making processes that influence the architecture and operation of the infrastructure. The state and condition in which an infrastructure operates influences the environment, and the environment, in turn, exerts pressure on the individual infrastructures. In a practical sense, infrastructures and their respective environments are interdependent [13].

In railway systems, a large number of delays are attributed to secondary delays that occur due to delay propagation - that is, the spread of delays in railway systems in time and space. Delay propagation is a result of operational and functional dependencies in railway systems. If a train incurs a delay early on, it is not possible to recover this delay - it will have this delay until it reaches its destination. This scenario highlights the interdependence of events in railway systems in which one primary delay can easily propagate to other systems within the network. Railway infrastructure systems must have the capacity to handle the traffic on the network by ensuring minimal delay propagation between scheduled trips. In a study to determine the correlation between the type and the age of railway infrastructure elements and the number of occurring system failures, Restel [14] identified infrastructure functional dependencies from the point of view that the most significant failure consequence is a delay. This study revealed the correlation between the type of infrastructure and the observed failure consequences in railway infrastructure systems. In a railway infrastructure environment, track infrastructure unreliability impacts on other subsystems of the railway network. In the manufacture of rails, various rigorous quality control processes are employed. However, these quality control measures do not extend to the site, and assets can be damaged by the time they arrive for installation. Installing misaligned or defective rails leads to poor track quality, which in turn damages the bogie and wheel sets of the rolling stock. These irregularities accelerate the rate of rail wear, and contribute to secondary damage in the overhead track equipment (OHTE) and pantograph subsystems.

In addition, factors such as operational procedures, business policies, and the functional relationships between infrastructure assets complicate the modelling and analyses of interdependencies in complex infrastructure systems [13].

\subsection{Characterising infrastructure dependence}

To develop a framework for modelling infrastructure interdependencies, there is a need to characterise these interdependencies and clarify the varying interpretations of 'interdependence' in the literature. Infrastructure interdependence can be defined as the bidirectional relationship between two infrastructures, in which the state of infrastructure $j$ influences the state of infrastructure $k$, or vice versa [15]. Additionally, infrastructure interdependence can be defined as the unidirectional relationship between infrastructure subsystems, in which the state of infrastructure $j$ depends on $k$, but the state of $k$ does not depend on $j$ [16]. The latter definition of dependency is often used synonymously with interdependence in the literature. From this perspective, it can be established that interdependencies are the macro-properties of multiple coupled systems that generally exist between the components of a particular system. Dependency, therefore, describes the relationships that exist on the micro-level of systems, in which the state of one or multiple components in a system depend on the state of the component(s) in another system. Thus, for two infrastructures in a system to be interdependent, each infrastructure subsystem must depend on the other within that system [15]. From this context, 'interdependencies' will be used in the study when discussing the coupled infrastructure systems from a macro standpoint, while 'dependency' will be employed when describing the relationship between infrastructure components.

The literature suggests varying frameworks and approaches to characterise and analyse infrastructure interdependencies. Fricks and Trivedi [17] suggested the classification of failure dependencies according to human error, system conditions, and inter-component dependency. 

into four distinct classes:

- $\quad$ physical (the state of each infrastructure system depends on the material outputs of another);

- cyber (the state of the system is dependent on the flow of information through an information infrastructure);

- geographic (two or more infrastructure systems that are spatially close being affected by the same local event); and

- $\quad$ logical (incorporates all other types of interdependencies, such as human behaviour).

Incorporating physical properties in the modelling of systems, in contrast to purely network analytical approaches, expands on the work that has been carried out in characterising infrastructure interdependencies. In a study of vulnerability analysis of interdependent critical infrastructures, Svegrup [18] highlighted that functional and geographic interdependencies exist between power transmission systems and the national railway system. The functional dependencies describe the dependence of railway systems on the electric power supply. On the other hand, the geographical dependencies describe the spatial proximity of power system components to the railway sections in a railway system.

\subsection{Modelling infrastructure dependencies}

Common reliability models assume that the lifetime or time-to-failure distributions of system components are statistically independent [17]. This assumption of independence is, however, breached in practice. For electronic systems, network systems and, in some cases, mechanical systems, the assumption of independence is almost always incorrect. Reliability models that only account for independent failures are likely to overestimate system reliability, and may provide misleading indications of the reliability performance of the system. The study by Fricks and Trivedi [17] showed that dependency influences the results of reliability models, and should never be ignored. Results from the same study showed that introducing human error and environmental constraints into reliability models provides a more realistic outlook when performing reliability evaluations for large systems. Different methods exist in modelling infrastructure dependencies. However, a different view point is necessary in order to address issues of infrastructure interdependencies comprehensively, as there is no universal, all-encompassing modelling approach [15]. To develop a predictive modelling approach, the important aspect is to focus on systematically and comprehensively establishing potential high consequence scenarios. A method to identify and assign ranks to critical components or sets of components in technical infrastructures was proposed by Jönsson, Johansson and Johansson [19]. The method maps and identifies the critical factors that influence the occurrence of high consequence scenarios in complex multi-state systems that exhibit interdependencies. The method facilitated the development of a model to identify critical failure sets and components of large complex technical infrastructures. Dunn and Wilkinson [20] used graph theory metrics to identify vulnerable areas within infrastructure systems. The graph theory can be used to provide predictive skills to identify vulnerable areas in a specific type of infrastructure system. This approach identifies the critical components in any given infrastructure system by representing the system as a graph consisting of nodes and links.

To investigate the effect of disturbances between systems, predictive models are employed to simulate and model the performance of a set of interconnected infrastructure systems. A wide range of these models is available, and represents different perspectives on ways to represent the system in question. Economic mathematical models and economic system dynamic models are examples of predictive approaches. Predictive approaches provide key information on the systems of interest, and facilitate the execution of a proactive approach to decision-making in infrastructure management. To complement predictive approaches, empirical approaches provide important insights into the patterns of infrastructure interdependence and into how failures link the different types of systems. Studying past events of infrastructure asset performance can help to develop an understanding of different infrastructure dependencies. Empirical approaches can identify patterns of interest to policy and decision-makers by studying the frequency of failures and the extent to which these affect the infrastructure system and operational processes. McDaniels et al. [21] developed an empirical framework to assess the different types of infrastructure dependencies to assist in prioritising decisions to reduce the likelihood and consequence of interdependent infrastructure failures. After observing that system reliability inevitably relates to that of the subsystems, Mokhtarian, Namzi-Rad, Ho and Suesse [22] used statistical methods to account for the uncertainties caused by interdependencies. It can be concluded that predictive and empirical 
approaches are complementary. Empirical studies form a general understanding of infrastructure interdependencies, and these results provide input for use by predictive models, policy, and decision-makers [15].

\section{RELIABILITY OF TRANSPORT INFRASTRUCTURE SYSTEMS}

Reliability is associated with dependability, and is unanimously regarded as a desirable transport network attribute [23]. Reliability can be defined as the probability that a system will perform its intended function for a specified period of time under a given set of conditions [24]. A strict definition of reliability accounts for four important aspects: probability, function, time, and the operating conditions. Typically, within the context of transport infrastructure, reliability is measured as the percentage of completed trips compared with the trips planned according to a published schedule. This leads to the definition of transport reliability: the ability of a transport system to provide the expected level of service on which users have organised their activities [23]. There is a clear distinction in reliability indicators for network quality (what is provided and planned) and the indicators of what the user experiences. These different perspectives are shown in Figure 1. For the network user, reliability focuses on the variability of travel times. The focus for the transport provider is on the infrastructure system's robustness and operating performance in relation to deviation from the expected level of service. This deviation is the measure of infrastructure unreliability, which can be attributed to unpredictable demand-related interactions and unanticipated supply-related events such as accidents, natural events, maintenance activities, and inappropriate maintenance programmes.

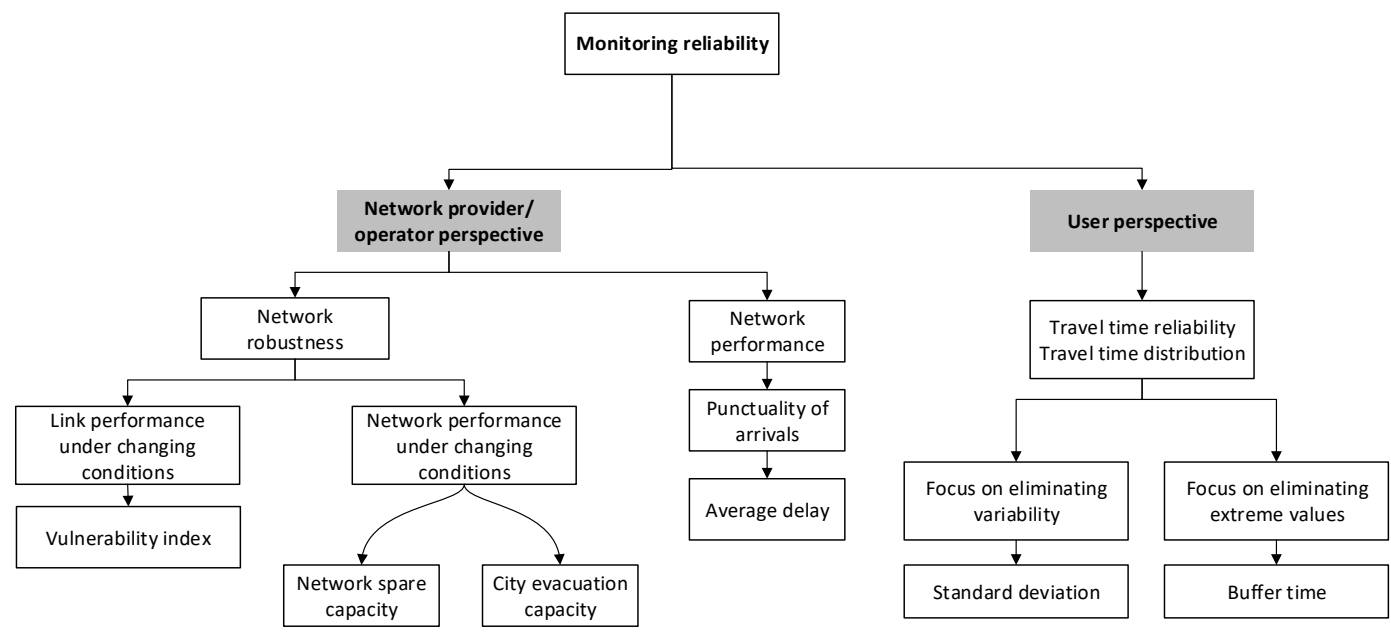

Figure 1 : Network and user perspectives on reliability [23]

Civil infrastructure systems have adopted reliability engineering in the design, operation, and maintenance stages of the asset's lifecycle. The techniques and procedures presented by reliability engineering make it applicable to analysing the performance of systems and identifying the root causes of system failures [25]. Carreras, Newman, Dobson and Zeidenberg [26] presented a simple reliability model of an infrastructure system that evolves over a long period, characterised by an increase in demand. Liang, Song and Chang [27] evaluated the performance and connectivity of urban infrastructure systems using analytical non-sampling-based network reliability models.

Additionally, to measure the performance of infrastructure assets under extreme hazards, Rokneddin [28] presented a reliability framework for a probabilistic risk assessment. In this study, the reliability model of the network is assigned a performance metric that indicates the level of performance of the interconnected infrastructure assets.

The approach to modelling the reliability of infrastructure systems is governed by many factors that depend on the characteristics of the system to be analysed. These include: 
- $\quad$ the topology and structural complexity of the system;

- $\quad$ the behaviour of system components;

- $\quad$ reliability indices required;

- $\quad$ the functional relationship between system components; and

- $\quad$ the type of system, and whether it is repairable or non-repairable.

\subsection{Modelling railway infrastructure reliability}

In modelling railway systems for reliability measure, it is important to distinguish between the system's ability to carry out a transportation task and the reliable operation of the system's components. Different infrastructure assets require different maintenance strategies. If the infrastructure assets constitute a larger system, it is important to understand the functional role of each infrastructure subsystem, the interactions between subsystems, and how they impact each other. This will enable reliability models to identify the factors that drive the reliability of railway infrastructure systems. Furthermore, the risks to and opportunities for the infrastructure system's reliability, which arise at the interfaces of the subsystems' boundaries, can be identified to realise the most cost-effective level of reliability for the entire railway system.

Different approaches have been proposed for modelling the reliability of railway infrastructure systems. A quantitative approach was proposed by Zhang, $\mathrm{Li}$ and $\mathrm{Li}$ [29] to analyse the criticality of elements in railway infrastructure systems. The modelling approach uses social network diagrams, with ties and nodes representing railway lines and train stations respectively. Stenstrom [30] proposed an approach to model, monitor, and analyse the operation and maintenance performance of railway infrastructure systems to facilitate railway infrastructure asset management. In a case study using railway transport, Tahmasseby and Nes [31] proposed a stochastic approach to measuring the impact of infrastructure on the reliability of urban rail transport networks. This was achieved by characterising connectivity reliability, defined as the probability that a network node remains connected, taking into account the interactions between the reliability of infrastructure systems and rolling stock subsystems in relation to the intensity of use. Franciszek [32] presented an approach to model the reliability of railway transport systems, concluding that for models with critical infrastructures, the unreliability of the system is contained in random streams of unwanted events. In these models, interference in the transportation process is taken into account only in the form of delays. Using importance measures with reference to a simple railway network system, Zio, Marella and Podofillini [33] demonstrated a method to determine high importance areas and to identify asset strategies that contribute the most towards system improvement. Nardone [34] proposed a methodology for the quantitative analysis of critical systems that integrates model-based evaluations with model-driven engineering (MDE) paradigms. The methodology was successfully applied to railway systems to quantify the reliability and availability of a railway passenger system.

A framework for modelling railway infrastructure reliability, based on the hierarchical representation of the railway network, was presented by Rama and Andrews [8], [35]. The model allows performance analysis to be conducted at varying levels of detail, ranging from an individual maintainable item to large multi-asset networks. The model consists of a hierarchical modular structure that is built from distinct asset models representing the next lowest hierarchical level. The distinct models are then used as building blocks for infrastructure models with varying levels of complexity. Information collected on asset degradation, infrastructure utilisation levels, and intervention strategies is used to determine the parameters of the model. Figure 2 shows the conceptual structure of the model. The modelling framework structure uses a top-down approach of looking at railway networks, operational routes, and railway lines between stations. Each line is then divided into sections, with each section consisting of a series of segments representing an infrastructure asset model. 


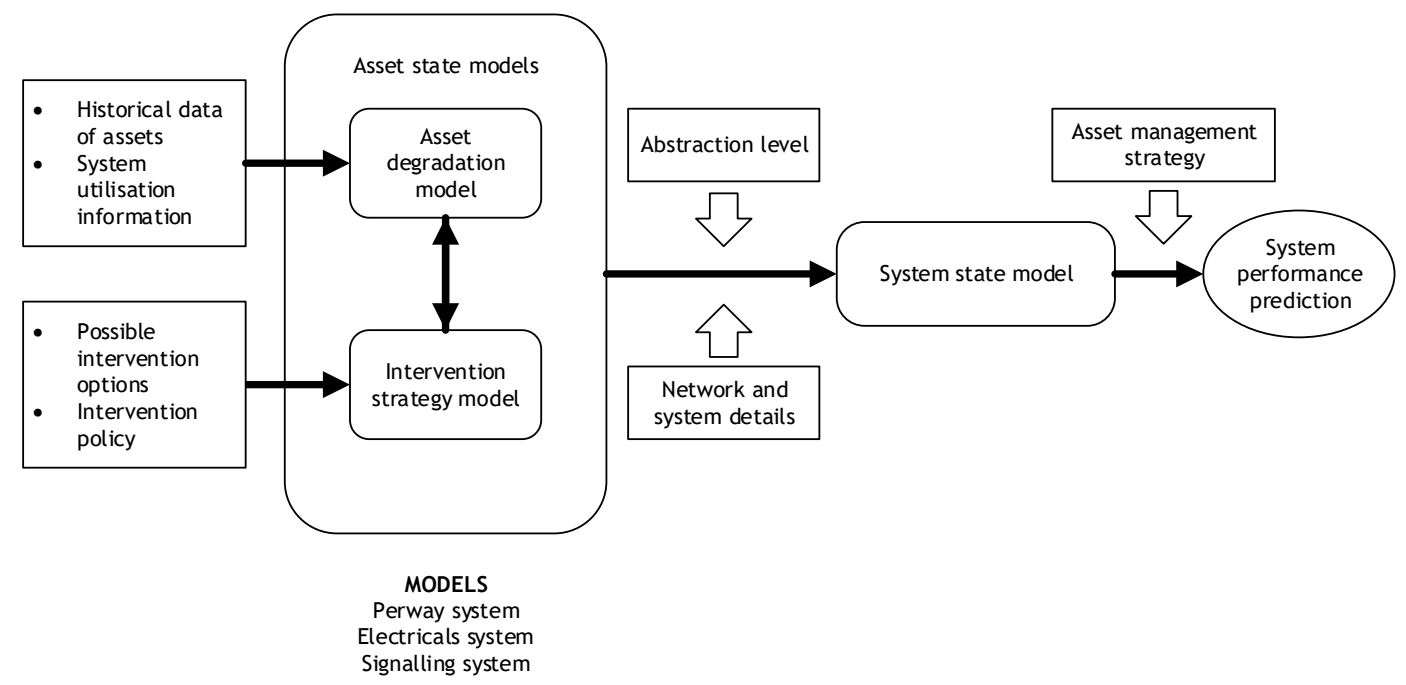

Figure 2 : A holistic approach to measuring the lifecycle performance of railway infrastructure assets (adopted from [35])

In modelling railway infrastructure reliability, Macchi et al. [36] took a family-based approach by emphasising that the most important aspect of a modelling approach is the relationship between railway system reliability and the transportation service level offered by the system itself. The twostep methodology builds families of similar items that possess the same reliability target and that can be standardised by infrastructure managers, as seen in Figure 3. Using system reliability analysis, the second step determines how the failure of infrastructure items impacts the service levels expected from the train's circulation. The methodology has been implemented and tested in practical case studies in the Rete Ferroviaria Italiana, the Italian public limited company for railway transportation.

MODELLING LEVEL ENTITIES CONTAINED IN THE MODEL RELIABILITY LOGICS

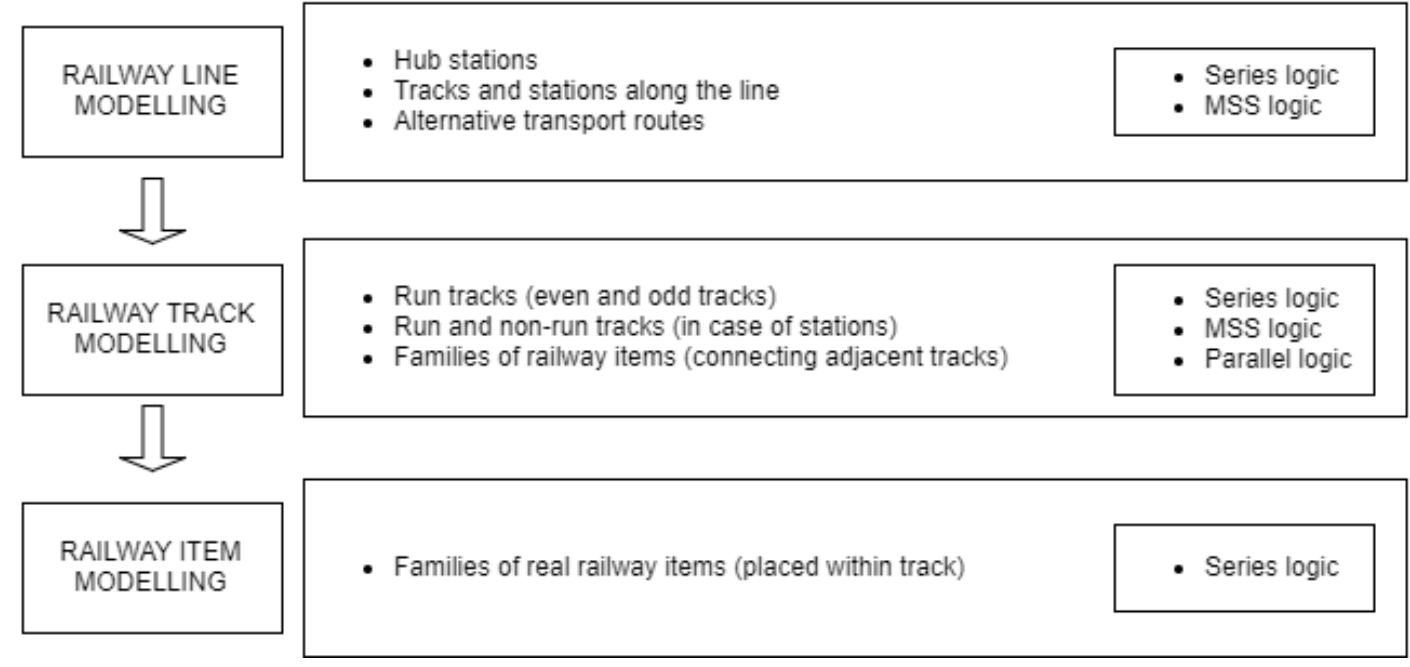

Figure 3 : Family-based approach to classifying railway infrastructure systems [36]

\section{DISCUSSION OF SOLUTION METHOD}

In this section, a possible holistic approach to be used in measuring the reliability of railway infrastructure is explored and proposed. Thus far, it is evident that several approaches exist to measure infrastructure reliability. The principle of continuous reliability improvement aspires to 
ever-increasing reliability performance. This implies that, regardless of the reliability levels achieved, infrastructure managers should continually strive to improve their reliability performance. This presents a contrasting picture to that of the current approach, in which reliability targets are seen as threshold values that limit the reliability that needs to be achieved. Decision-making in asset management requires knowledge and understanding of asset performance and the expected intervention processes. This is evident in railway infrastructure asset management, in which decisions are made at varying levels of complexity. These decisions influence possible asset management options that impact infrastructure performance and the exposure to risk for individuals and assets and the broader infrastructure network. A model that has the ability to express outcomes of various intervention plans at the different hierarchical levels of the network is recommended. This can be achieved by using closed form and simulation-based methods that incorporate the deterministic and stochastic properties of railway infrastructure systems.

The recurring theme from existing infrastructure reliability models is that of identifying and categorising system components as a fundamental step to configure the topology of railway infrastructure systems accurately. To identify the infrastructure subsystems requires a modelling technique that can classify the infrastructure system according to its respective components. A family-based approach to categorising the infrastructure components can be adopted to establish the components of each of the infrastructure subsystems. Furthermore, a hierarchical approach representing the functional relationship between the subsystems can be adopted to highlight the components in each subsystem. By recognising a railway as a system, the unreliability that arises at the subsystem interfaces can be clearly defined. By studying the railway infrastructure system as a black box, the reliability metrics of the system can be estimated in a more general way. The goal, however, is to model the system in terms of reliability aspects that are consistent with railway infrastructure performance measures. The effect of an unreliable transport system is characterised by excessive delays and trip cancellations. Relating the impact of infrastructure performance to the quality of service (punctuality, safety, and affordability), the contribution of the infrastructure system to service disruption can be established. Thereafter, the reliability of the system can be evaluated by analysing the performance of the subsystems that constitute the railway infrastructure system. This means that, from the values of the failure rate from individual system components, including the mean time between failures (MTBF), one can determine values referring to the systems performance and interaction with environment. This performance is observed through delays and service cancellations.

An ideal reliability model should capture the conditions that cause system failure in the functional and operational relationships of the railway infrastructure system. The derived functional relationships between system components will formulate the basic structure of the reliability model, and can be used to characterise the dependencies that impact infrastructure performance. This approach accounts for the sensitivity caused by the interdependencies within the infrastructure system, making it possible to establish the reliability importance of the components or subsystems in the infrastructure system. Additionally, reliability is closely related to robustness and systems integrity, which presuppose that there is at least one control structure inherent in a system, and that this can be qualitatively tested and quantified. A dual control structure approach is one in which the system is modelled holistically, but not in its entirety. To take this approach economically requires contextualising the scenario in which the reliability model is applied. This is to address the applicability of either a generic model or a model specific to a particular organisation. Thereafter, a standard modelling ontology approach can be used to develop models for each of the subsystems, which in turn can be used to identify the core system models of the infrastructure system. The core system models can be integrated with the dual control systems, which are a priority in terms of criticality or systems (components). The priority components are fundamentally the model constraints. This approach will provide the robustness that can improve the reliability being evaluated. Once normalised, the next step would be to identify the driving forces within the overall model. These driving forces are the critical core components, associated components, and operational relationships between subsystems.

The underlying objective of applying reliability-based techniques in railway infrastructure management is to achieve high infrastructure performance at lower costs. A multi-criteria approach to evaluating the performance of infrastructure assets is based on the contribution each railway infrastructure subsystem makes to delivering the projected quality of service. Adopting a reliabilitybased approach to railway infrastructure asset management with the aim of improving the performance of infrastructure assets follows a whole-systems approach, as seen in Figure 4 . It is 
evident that the problem of modelling complex systems that exhibit interdependence requires a multidisciplinary approach to account for all the possible factors that influence interdependence. Furthermore, to increase the fidelity of the models for railway infrastructure systems, it is necessary to develop functional models with the cooperation of stakeholders and expertise from each of the infrastructure subsystems, and to use existing knowledge of how these systems function. Thus the application of reliability modelling to railway infrastructure systems must be supported by case studies from the railway industry. Understanding the system functionality by applying systems engineering principles is an initial step towards adopting reliability-based techniques in railway infrastructure management. Furthermore, the strategic objectives of the infrastructure asset management policies must use a reliability-centred approach to complement efforts towards realising a reliable infrastructure system. Frameworks such as reliability-centred maintenance (RCM) and the reliability, availability, maintainability and safety (RAMS) framework have been developed to improve the reliability performance of infrastructure assets.

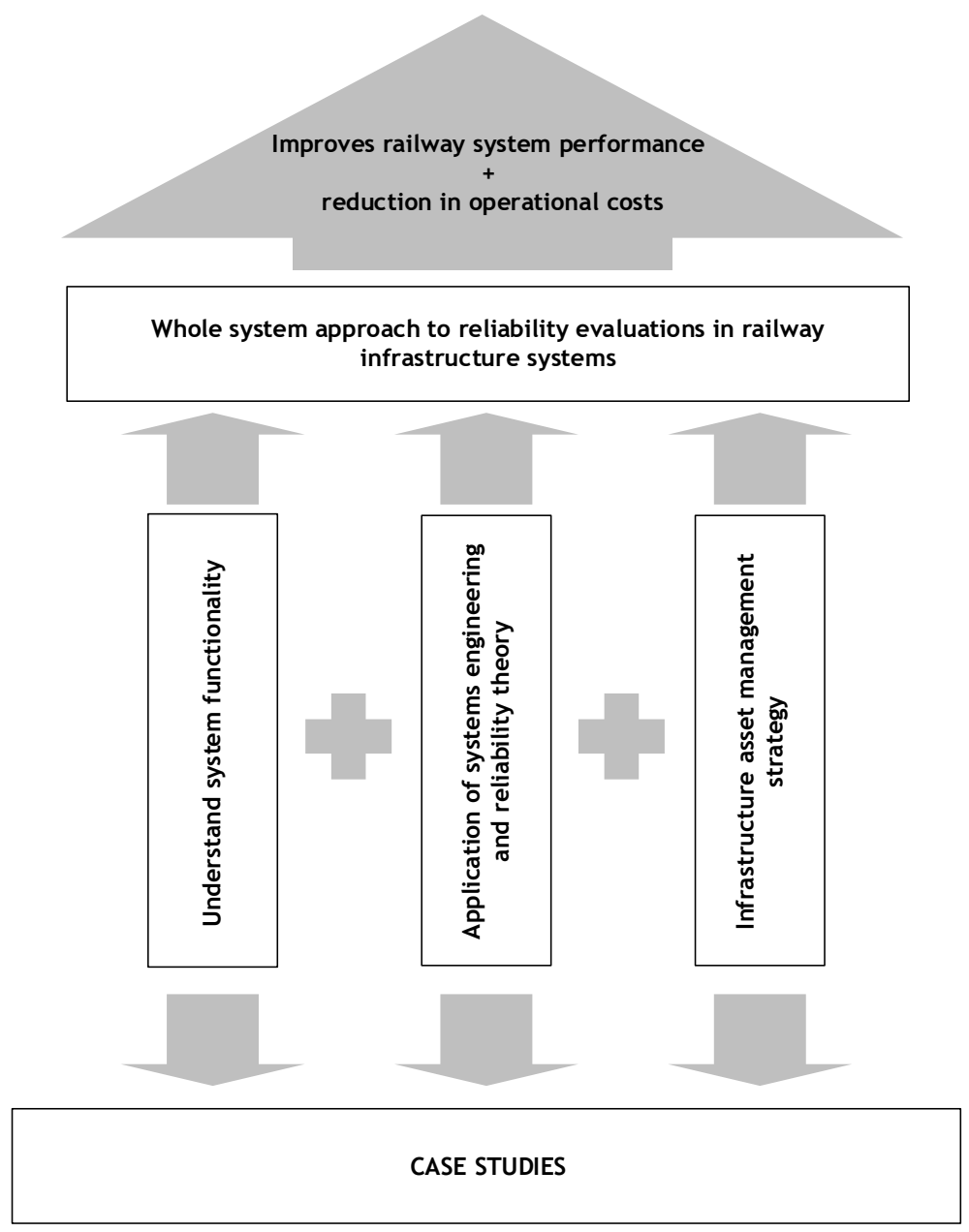

Figure 4 : Framework for applying a reliability-based approach to railway infrastructure management

\section{CONCLUSION}

The underlying objective of applying reliability-based techniques in railway infrastructure management is to achieve high infrastructure performance at lower costs. This paper presents a modelling framework to express outcomes of various physical intervention plans at the different hierarchical levels of a railway infrastructure network. The paper expands on the work that has been carried out in characterising infrastructure dependencies. The framework presented is a wholesystems approach incorporating functional and operational properties in the modelling of railway infrastructure systems. This multi-criteria approach to evaluating the performance of infrastructure 
assets accounts for the contribution of each railway infrastructure subsystem in delivering the projected quality of service. Three principles emerge from developing a holistic approach for modelling the reliability of railway infrastructures systems. Studying the impact of interdependencies in technical infrastructures in a holistic manner requires, firstly, an understanding of the operational and functional characteristics of the system. Secondly, applying principles of system engineering will ensure that the understanding of the system can be translated into processes that improve the reliability aspects of the system. Modelling complex systems that exhibit interdependence requires a multidisciplinary approach to account for all the possible factors that influence interdependence. Lastly, strategies for railway infrastructure asset management should be reliability-centred, ensuring the continuous improvement of the reliability of infrastructure performance.

\section{REFERENCES}

[1] McNaught, M. D. 2015. 'A Risk-Reliability Comparison Of Track Sections In The Passenger Railway Industry,' Urban Transport Conference, Valencia.

[2] Jidayi, Y. M. 2015. 'Reliability Improvement of Railway Infrastructure,' Stellenbosch University.

[3] Conradie P. D., Fourie C., Vlok P., and Treurnicht N. 2015. 'Quantifying System Reliability in Rail Transportation in an Aging Fleet Environment,' The South African Journal of Industrial Engineering, vol.26, no. March, p. 128-142.

[4] Panja, S. C. and Ray, P. K. 2007. 'Reliability Analysis of a "Point-and-Point Machine" of the Indian Railway Signaling System,' Quality and Reliability Engineering International, vol. 23, no. November, pp. 517-543.

[5] Ho, T., Chen, S. and Mao, B. 2006. 'Application on Fault Tree Analysis in Railway Power Supply Systems,' in proceedings of 5th International Conference on Traffic and Transportation Studies, Science Press, Xian.

[6] Chen, S. K., Ho, T. K. and Mao, B. H. 2007. 'Reliability evaluations of railway power supplies by faulttree analysis,' IET Electric Power Applications, vol.1, no. 5, pp. 643-656.

[7] Ku, B.H. and Cha, J.M. 2011. 'Reliability assessment of Catenary of Electric railway by using FTA and ETA analysis,' in proceedings of 10th International Conference on Environment and Electrical Engineering, IEEE, pp. 1-4.

[8] Rama, D. and Andrews, J. D. 2016. 'Railway infrastructure asset management: the whole-system life cost analysis,' IET Intelligent Transport Systems, vol.10, no. 1, pp. 58-64.

[9] Grubesic, T. H. 2009. 'The Management and Measurement of Infrastructure: Performance, Efficiency and Innovation,' Growth and Change, vol.40,no. 1, pp. 184-187.

[10] Rail System and Communications Department. 2010. 'Guidelines for the Application of Asset Management in Railway Infrastructure Organisations,' International Union of Railways, Paris.

[11] Steenbergen, R. D. J. M., Van Gelder, P.H.A.J.M., Miraglia, S., Vrouwenvelder A.C.W.M. 2012. 'Safety, Reliability and Risk Analysis : Beyond The Horizon,' CRC Press.

[12] Ching, J. and Leu, S.S. 2009. 'Bayesian updating of reliability of civil infrastructure facilities based on condition-state data and fault-tree model,' Reliability Engineering and System Safety, vol.94, no.12, pp. 1962-1974.

[13] Rinaldi, S. M. 2004. 'Modeling and simulating critical infrastructures and their interdependencies,' in proceedings of 37th Annual Hawaii International Conference on System Sciences, IEEE, Hawaii.

[14] Restel, F. J. 2013. 'Impact of infrastructure type on reliability of railway transportation system,' Journal of KONBiN, vol.1, no.25, pp. 21-36.

[15] Johansson, J. and Hassel, H. 2010. 'An approach for modelling interdependent infrastructures in the context of vulnerability analysis,' Reliability Engineering \& System Safety, vol.95, no.12, pp. 1335-1344.

[16] Rinaldi, S. M., Peerenboom, J. P. and Kelly, T. K. 2001. 'Identifying, understanding, and analyzing critical infrastructure interdependencies,' IEEE Control Systems, vol.21, no.6, pp. 11-25.

[17] Fricks, R. M. and Trivedi, K. S. 1997. 'Modeling failure dependencies in reliability analysis using Stochastic Petri-nets', in Proceedings of European Simulation Multiconference (ESM 97).

[18] Svegrup, L. and Johansson. J. 2015. 'Vulnerability analyses of interdependent critical infrastructures: Case study of the Swedish national power transmission and railway system,' Safety and Reliability of Complex Engineered Systems, ESREL 2015, pp. 4499-4507.

[19] Johansson, J. and Hassel, H. 2010. 'An approach for modelling interdependent infrastructures in the context of vulnerability analysis,' Reliability Engineering \& System Safety, vol.95, no.12, pp. 1335-1344.

[20] Dunn, S. and Wilkinson, S. M. 2013. 'Identifying Critical Components in Infrastructure Networks Using Network Topology,' Journal of Infrastructure Systems. American Society of Civil Engineers, vol.19, no.2, pp. 157-165.

[21] McDaniels,T., S. Chang, S., Peterson,K., Mikawoz,J. and Reed,D. 2007. 'Empirical Framework for Characterizing Infrastructure Failure Interdependencies,' Journal of Infrastructure Systems. American Society of Civil Engineers, vol.13, no.3, pp. 175-184.

[22] Mokhtarian,P., Namzi-Rad M.R., Ho T. K., and Suesse T. 2013. 'Bayesian nonparametric reliability analysis for a railway system at component level,' in 2013 IEEE International Conference on Intelligent Rail Transportation (ICIRT) Proceedings. pp. 197-202.

[23] Transport Research Centre. 2010. Improving Reliability on Surface Transport Networks. International Transport Forum and Organisation for Economic Co-operation and Development (OECD), Paris. 
[24] Lewis, E.E. 1987. Introduction to reliability engineering., Wiley, New York.

[25] Human, E. 2012. 'What is Reliability Engineering,' Asset Management \& Reliability Engineering, (June), pp. 3-5.

[26] Carreras B. A., Newman D. E., Dobson I., and Zeidenberg M. 2009. 'A simple model for the reliability of an infrastructure system controlled by agents,' 42nd Hawaii International Conference on System Sciences, Big Island HI.

[27] Liang, C., Song, J. and Chang, L. 2007. 'Matrix-based System Reliability Analysis of Urban Infrastructure Networks: A Case Study of MLGW Natural Gas Network,' in Fifth China-Japan-US Trilateral Symposium on Lifeline Earthquake Engineering, Haikou, China.

[28] Rokneddin, K. 2013. 'Reliability and Risk Assessment of Networked Urban Infrastructure Systems Under Natural Hazards,' Rice University, USA.

[29] Zhang, Z., Li, X. and Li, H. 2015. 'A quantitative approach for assessing the critical nodal and linear elements of a railway infrastructure,' International Journal of Critical Infrastructure Protection, vol.8, pp. 3-15.

[30] Stenstrom, C. 2014. 'Operation and maintenance performance of rail infrastructure: Model and Methods,' Luleå University of Technology, Sweden.

[31] Tahmasseby, S. and Van Nes, R. 2008. 'Impacts of infrastructures on reliability of urban rail bound public transport networks,' Urban Transport, vol.15, pp. 185-194.

[32] Restel F.J. 2015. 'Defining States in Reliability and Safety Modelling'. In: Zamojski W., Mazurkiewicz J., Sugier J., Walkowiak T., Kacprzyk J. (eds) Theory and Engineering of Complex Systems and Dependability. Advances in Intelligent Systems and Computing, vol.365, Springer, Cham.

[33] Zio, E., Marella, M. and Podofillini, L. 2007. 'Importance measures-based prioritization for improving the performance of multi-state systems: application to the railway industry,' Reliability Engineering \& System Safety, vol.92, no.10, pp. 1303-1314.

[34] Nardone, R. 2013. 'A Model-Driven Approach to Quantitative Analysis of Critical Systems,' University of Naples Federico II, Italy.

[35] Rama, D. and Andrews, J. D. 2014. 'A Holistic Approach to Railway Infrastructure Asset Management,' International Journal of Performability Engineering, vol.11, no.2, pp. 107-120.

[36] Macchi M., Garetti M., Centrone D., Fumagalli L., and Piero Pavirani G. 2012. 'Maintenance management of railway infrastructures based on reliability analysis,' Reliability Engineering \& System Safety, vol.104, pp. 71-83. 